При формуванні алгоритму контролю технічного стану генераторів водню в якості вихідних даних використовуються їх амплітудно-частотні та фазово-частотні характеристики. При використанні класичного методу визначення таких характеристик мають місце декілька недоліків. Одним із суттевих недоліків є великий час, який необхідний для формування масиву вихіднх даних. Для скорочення ивого часу визначення частотних характеристик генератора водню здійснюється за результатами вимірювань його перехідноі функції в дискретні моменти часу. В иі моменти часу перехідна функиія апроксимуеться функціями Хевісайда. Такий підхід дозволяє скоротити час визначення частотних характеристик генератора водню на 1-2 порядки. Використання теореми Котельнікова-Найквиста-Шеннона для визначення цих дискретних моментів часу пов'язано із невизначеністю стосовно максимальної частоти спектру тест-сигналу.

Для зняття иієї невизначеності вибір дискретних моментів часу для виміру перехідної функиіі генератора водню здійснюється за умови допустимої похибки їі апроксимачії.

Похибка апроксимачії визначаеться за результатом розв'язання тест-задачі, в якій в якості еталону иастотних характеристик використовуються модельні характеристики. Показано, що при інтервалі дискретності $(0,25 \div 2,5)$ мс величина такої похибки не перевищує $1,7 \%$.

Враховано інериійні властивості пристрою для формування тест-впливу. Показано, що доцільність використання такої процедури має місце, якщо еквівалентна постійна часу такого пристрою перевищує величини постійних часу генератора водню. Інерційні властивості враховані иляхом введення додаткового множника, який містить еквівалентну постійну часу пристрою, в аналітичних виразах для частотних характеристик генератора водню

Ключеві слова: генератор водню, вихідні дані, частотні характеристики, тест-задача, похибка апроксимації
Received date 23.09.2019

Accepted date 22.10.2019

Published date 28.10.2019
UDC $661.961 ; 861.968$

DOI: $10.15587 / 1729-4061.2019 .181417$

\title{
DETERMINING THE SOURCE DATA TO FORM A CONTROL ALGORITHM FOR HYDROGEN GENERATORS
}

\author{
Yu. A bramov \\ Doctor of Technical Sciences, Professor, Chief Researcher \\ Research Center* \\ E-mail: abramov121146@gmail.com \\ O. B a s m a nov
}

Doctor of Technical Sciences, Professor, Chief Researcher Scientific Department of Problems of Civil Protection and Technogenic-Ecological Safety of the Research Center*

E-mail: oleksii.basmanov@nuczu.edu.ua

V. Krivtsova

Doctor of Technical Sciences, Professor Department of Physical and Mathematical Disciplines* E-mail: krivtsovav53@gmail.com

A. Mikh a y l u k

$\mathrm{PhD}$, Senior Researcher Department of Doctoral Studies, Adjuncture*

E-mail: mihayluk.nuczu@gmail.com

0. Mi k h a y l u k

$\mathrm{PhD}$, Associate Professor

Department of Fire and Technogenic Safety

of Objects and Technologies*

E-mail:50lexa35@ukr.net

*National University of Civil Defence of Ukraine Chernyshevska str., 94, Kharkiv, Ukraine, 61023

Copyright (C) 2019, Yu. Abramov, O. Basmanov, V. Krivtsova, A. Mikhayluk, O. Mikhayluk. This is an open access article under the CC BY license (http://creativecommons.org/licenses/by/4.0)

\section{Introduction}

Improvements in energy systems can be achieved by using hydrogen as a working body [1]. The utilization of hydrogen in the on-board energy systems becomes particularly relevant in this case. A characteristic feature of this type of systems is the inclusion of hydrogen storage and supply systems, whose main element is a hydrogen generator, in particular, based on the use of hydro-responsive compounds [2]. The safe operation of such hydrogen storage and supply systems implies ensuring its parameters and characteristics that would warrant compliance with the regulatory requirements [3]. This circumstance necessitates the implementation of algorithms to control their technical condition. In this regard, it is a relevant task to ensure the conditions for implementing the algorithms to monitor the technical condition of hydrogen storage and supply systems. At the same time, one of these conditions is the preparation of source data to form control algorithms.

Employing the classical method for determining the frequency characteristics of a hydrogen generator, which are the source data for the formation of algorithms to control its technical condition, implies the measurements of its output signal whose number reaches tens or hundreds. In this case, the time for each measurement should equal at least the time of the transition process. In this regard, one of the areas in which the technical condition of a hydrogen generator is improved is to reduce the time it takes to produce its source data. Such a reduction could be achieved, for example, by using the time-specific characteristics of a hydrogen generator to determine its frequency characteristics. In this case, there are opportunities to reduce the time it takes to determine the original data by tens and hundreds of times. 


\section{Literature review and problem statement}

A significant task when utilizing a hydrogen fuel is the construction of hydrogen storage and supply systems [4]. It is particularly important to address this problem for onboard energy systems. Paper [5] provides information on hydrogen storage systems based on the hydrides of metals and intermetallides, as well as considers design solutions for thermolysis and hydrolysis. Technical solutions for monitoring the processes of thermolysis and hydrolysis remained unaddressed in the cited paper. Endothermic dehydration of metal hydride is used to improve the safety of hydrogen storage and supply systems [6]. However, there are a series of problems related to providing sufficient hydrogen reserves for the stable operation of a power plant. Study [7] notes that hydrogen evolution by hydrolysis may be accompanied by releasing a large amount of heat - up to $15.0 \mathrm{MJ} \cdot \mathrm{kg}^{-1}$. Such a generation mode does not rule out a possibility of an emergency [8]. In order to weaken this possibility, temperature in the working cavity of a hydrogen generator is monitored [7]. Sensors of this type have a relay static characteristic, which leads to the implementation of the simplest control algorithms. Such algorithms enable control over the technical condition of a hydrogen storage and supply system based on a yes-no principle. The quantitative estimates of the parameters and characteristics of the systems that include a hydrogen storage and supply system are given in paper [9]. However, such assessments are based on the results from one-off tests. Study [10] considers one of the options for constructing nanosatellites using aluminum hydrides and borohydrides as combustible components. However, the study does not address the control over parameters of the process. The authors of paper [11] suggest a procedure for evaluating the effectiveness of a hydrogen generator, taking into consideration the requirements to the power of support systems. In addition, they report results from laboratory experiments involving a hydrogen generator, which contains a water electrolyzer for a wide range of loads on the device. The resulting characteristics serve as the source material to analyze the Power-to-Gas system. These characteristics are not used to assess the technical condition of the device. A similar approach is taken in paper [12], in which, for the case of an electrolyzer with a proton-exchange membrane, the dynamic characteristics of the hydrogen storage and supply system are determined. The industrial samples of hydrogen generators typically employ control over one or two parameters of the hydrogen generation process [13]. In most cases, the parameters that characterize the local properties of hydrogen generators are monitored. Paper [14] proposes an algorithm to control the technical condition of hydrogen generators based on hydro-responsive compounds. A feature of such a control algorithm is the use, as source data, of the value for the amplitude-frequency characteristic of a hydrogen generator at a fixed frequency. Implementation of such an algorithm of control does not make it possible to receive information about the technical condition of a hydrogen generator over the entire range of working frequencies. This flaw has been overcome by the algorithm to control the technical condition of a hydrogen generator, which is described in paper [15]. The starting material for the implementation of such a control algorithm is the phase-frequency characteristic of a hydrogen generator. This frequency characteristic is determined by taking into consideration the Kotelnikov-Nyquist-Shannon theorem, which offers the a priori defined magnitudes for the maximum frequency of the test-impact spectrum. This approach to determining the frequency characteristic does not make it possible to clearly define the number of measurements to form the source data for a control algorithm. In this regard, among the problems associated with the formation of algorithms to control the technical condition of hydrogen generators is the task on determining the source data for the implementation of such algorithms.

\section{The aim and objectives of the study}

The aim of this study is to determine the raw data for the formation of an algorithm to control the technical condition of a hydrogen generator, which uses its frequency characteristics.

To accomplish the aim, the following tasks have been set:

- to construct a method for defining the raw data in order to form a control algorithm based on the use of the temporal characteristic of a hydrogen generator;

- to determine the requirements for selecting a sampling interval when forming a data set;

- to consider the effect of the inertial properties of the testimpact device on the outcome of determining the source data.

\section{Construction of a method for determining raw data to form a control algorithm}

The source data that underlie the formation of algorithms for controlling the technical condition of hydrogen storage and supply systems could be based on the parameters and characteristics for both static and dynamic modes of their operation. Papers [14,15] employ the frequency characteristics in order to construct algorithms to control hydrogen generators.

Let us consider a procedure for determining the frequency characteristics of a hydrogen generator, which is based on an indirect method. The essence of the method is as follows:

- it is assumed that the test impact is a jump-like change in the area of the hydrogen generator outlet hole, that is such an impact can be described by the Heaviside function;

- the hydrogen generator's response to this impact is a transition function;

- the transitional function is measured over equal discrete time moments, that is an array of data is formed to conduct a computational procedure;

- a conversion operator is formed to move from the parameters of temporal domain to the parameters in frequency domain;

- by using a formed dataset and the conversion operator, the frequency characteristics of a hydrogen generator are calculated.

It should be noted that the time of implementation of such a procedure does not exceed the time of the transition process of the hydrogen generator.

To determine the transition function of a hydrogen generator, the output hole area is changed according to expression

$$
F(t)=B \cdot 1(t),
$$

where $B=$ const; $1(t)$ is the Heaviside function. 
A transition function would take the form shown in Fig. 1 with a solid line, that is it would represent the dependence of pressure increment $P(t)$ in the hydrogen generator cavity on time.

Function $\mathrm{P}(\mathrm{t})$ can be approximated by expression

$$
P(t)=\sum_{k=0}^{n} \Delta_{k} \cdot 1(t-(k+0.5) \tau),
$$

where $\tau$ is the interval of discreteness; $\Delta_{k}$ is the increment of pressure in the hydrogen generator cavity over time interval $(k+1) \tau \div k \tau$.

By applying the integrated Laplace transformation to expression (2), we obtain

$$
P(S)=S^{-1} \sum_{k=0}^{n} \Delta_{k} \exp [-S(k+0.5) \tau]
$$

where $S$ is a complex variable.

The integrated transfer function of a hydrogen generator will then be determined by expression

$$
\begin{aligned}
& \text { asdf } W(j \omega)=P(j \omega)[F(j \omega)]^{-1}= \\
& =B^{-1} \sum_{k=0}^{n} \Delta_{k} \exp [-j \omega(k+0.5) \tau]= \\
& =B^{-1} \sum_{k=0}^{n} \Delta_{k}[\cos [\omega(k+0.5) \tau]-j \sin [\omega(k+0.5) \tau]]
\end{aligned}
$$

where $j$ is an imaginary unit; $\omega$ is the circular frequency; $F(S)$ is the Laplace representation of function $\mathrm{F}(\mathrm{t})$, which is described by expression (1).

Expressions for the frequency characteristics of a hydrogen generator follow from (4): $A(\omega)$ are the amplitude-frequency characteristics (AFC) and $\varphi(\omega)$ are the phase-frequency characteristics (PFC).

$$
\begin{aligned}
& A(\omega)=|W(j \omega)|=B^{-1}\left[\left[\sum_{k=0}^{n} \Delta_{k} \cos [\omega(k+0.5) \tau]\right]^{2}+\right. \\
& \left.+\left[\sum_{k=0}^{n} \Delta_{k} \sin [\omega(k+0.5) \tau]\right]^{2}\right]^{0,5} ; \\
& \phi(\omega)=\arg W(j \omega)= \\
& =-\operatorname{arctg}\left[\left[\sum_{k=0}^{n} \Delta_{k} \sin [\omega(k+0.5)] \tau\right] \times\right. \\
& \left.\times\left[\sum_{k=0}^{n} \Delta_{k} \cos [\omega(k+0.5) \tau]\right]^{-1}\right] .
\end{aligned}
$$

The formation of source data for the hydrogen generator control algorithm, for which we use frequency characteristics (5) and (6), necessitates the choice of the parameter $\tau$, the interval of discreteness. To select this parameter, one can use the Kotelnikov-Nyquist-Shannon theorem, which requires that

$$
\tau=0.5 f_{m}^{-1},
$$

where $f$ is the maximum frequency of the function $P(t)$ spectrum.

It should be noted that in contrast to the classic method for determining the frequency characteristics of a hydrogen generator, whose time of determination is two to three orders of magnitude longer than the transition process time, the time for determining such characteristics when using such characteristics does not exceed the time of the transition process. Thus, the effectiveness of using the proposed method is higher than that when using the classical method by $2-3$ orders.

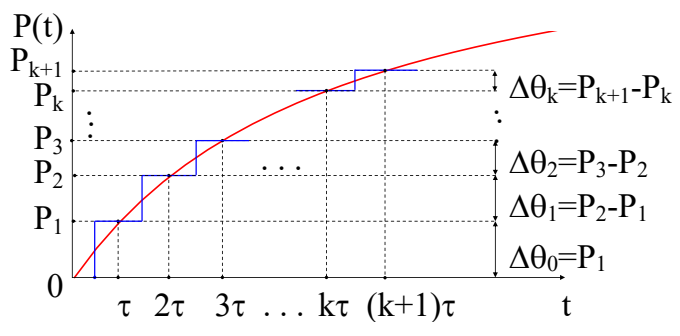

Fig. 1. Determining the frequency characteristics of a hydrogen generator

\section{Defining the requirements for choosing a discreteness} interval when forming a data array

In order to define the requirements to the discreteness interval of the array of source data, it is advisable to solve a test problem. Solving this problem implies using expressions (5), (6) in order to determine the source data, provided that the discrete interval is variable and the margin of error in determining the source data does not exceed the required value.

It should be noted that the choice of $f_{m}$ frequency does not have an unambiguous solution, because in order to select it, it is necessary to stipulate the value of a spectral characteristic at this frequency. In this case, there is uncertainty in the margin of error, which is due to the discrete nature of function (2). To address these difficulties, it is advisable to choose the magnitude for parameter $\tau$ from the condition for ensuring a permissible error of discredit.

To solve this problem, we shall determine the reaction of a hydrogen generator to the test-impact described by expression (1). This reaction will be described by expression

$$
P(t)=L^{-1}[W(S) F(S)],
$$

where $L^{-1}$ is the operator of the Laplace reverse transformation; $W(S)$ is the transfer function of a hydrogen generator; $F(S)$ is the Laplace representation of function $F(t)$.

Given that expression [15] holds for a hydrogen generator

$$
W(S)=K\left(1-\tau_{1} S\right)\left[\left(\tau_{2} S+1\right)\left(\tau_{3} S+1\right)\right]^{-1}
$$

where $K$ is the transfer ratio; $\tau_{i}$ is the $i$-th time constant, and for $F(S)$

$$
F(S)=B S^{-1}
$$

one can record, for a hydrogen generator reaction, in the form of a single transition function

$$
\begin{aligned}
& P(t)=P(t)(B K)^{-1}=1+\left(\tau_{3}-\tau_{2}\right)^{-1} \times \\
& \times\left[\left(\tau_{1}+\tau_{2}\right) \exp \left(-\frac{t}{\tau_{2}}\right)-\left(\tau_{1}+\tau_{3}\right) \exp \left(-\frac{t}{\tau_{3}}\right)\right] .
\end{aligned}
$$

This expression was treated with discredit operator (2), and the values for time constants $\tau_{i}$ were accepted to be equal to: 
$\tau_{1}=7.9 \mathrm{~ms} ; \tau_{2}=6.5 \mathrm{~ms} ; \tau_{3}=14.4 \mathrm{~ms}$.

The magnitude for parameter $\tau$ varied in the range $(0.25 \div 2.5) \mathrm{ms}$.

The result of implementing this procedure was the formation of an array of data with respect to $\Delta_{k}, k=0,1, \ldots, n$ for algorithms (5) and (6) at $B=1.0$.

In order to compare results obtained in accordance with expressions (5) and (6), we used reference values for amplitude-frequency characteristic $A_{0}(\omega)$ and phase-frequency characteristic $\varphi_{0}(\omega)$ of a hydrogen generator. Frequency characteristics corresponding to transfer function (9) were used as reference frequency characteristics, that is

$$
\begin{aligned}
& A_{0}(\omega)=\left[M^{2}(\omega)+N^{2}(\omega)\right]^{0.5} ; \\
& \phi_{0}(\omega)=\arctan \left[N(\omega)[M(\omega)]^{-1}\right],
\end{aligned}
$$

where

$$
\begin{aligned}
& M(\omega)=\left[1-\omega^{2}\left(\tau_{1} \tau_{2}+\tau_{1} \tau_{3}+\tau_{2} \tau_{3}\right)\right] \times \\
& \times\left[1+\omega^{2}\left(\tau_{2}^{2}+\tau_{3}^{2}+\omega^{2} \tau_{2}^{2} \tau_{3}^{2}\right)\right]^{-1} ; \\
& N(\omega)=-\omega\left(\tau_{1}+\tau_{2}+\tau_{3}-\omega^{2} \tau_{1} \tau_{2} \tau_{3}\right) \times \\
& \times\left[1+\omega^{2}\left(\tau_{2}^{2}+\tau_{3}^{2}+\omega^{2} \tau_{2}^{2} \tau_{3}^{2}\right)\right]^{-1} .
\end{aligned}
$$

Mismatch errors for the AFC and PFC of a hydrogen generator were determined from expressions

$$
\begin{aligned}
& \delta_{A}=1-A(\omega)\left[A_{0}(\omega)\right]^{-1} ; \\
& \delta_{\phi}=1-\phi(\omega)\left[\phi_{0}(\omega)\right]^{-1}
\end{aligned}
$$

Fig. 2 shows examples of the distribution of errors $\delta_{A}$ and $\delta_{\varphi}$ in the range of frequencies $\omega=(0 \div 400) \mathrm{s}^{-1}$ at $\tau=1.25 \mathrm{~ms}$.

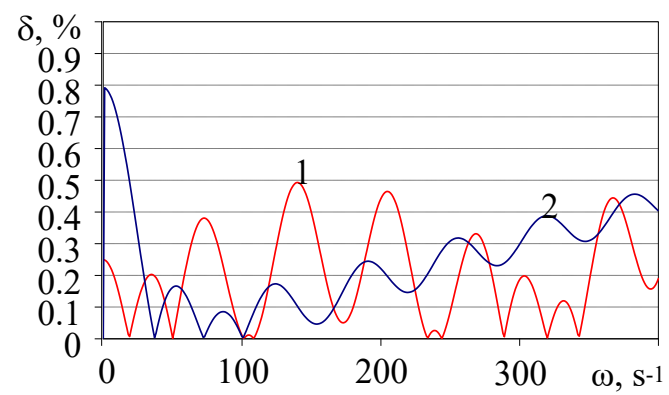

Fig. 2. Mismatch error: 1 - amplitude $\delta_{A} ; 2$ - phase $\delta_{\varphi}$

Fig. 3 shows dependences for the maximum values of error (16) and (17) at $k=0.01 \div 0.1$, where $k$ is the factor in ratio

$\tau=k \tau_{0}, \quad \tau_{0}=25 \mathrm{~ms}$.

It follows from an analysis of Fig. 3 that when selecting $\tau=(0.25 \div 2.5) \mathrm{ms}$ the maximum value of a mismatch error for the AFC of a hydrogen generator does not exceed $1.4 \%$, and for a mismatch error for PFC does not exceed $1.7 \%$. Such error values in the formation of source data to assess the technical condition of hydrogen generators do not exceed permissible values, which in practice are about $5-6 \%[12]$.

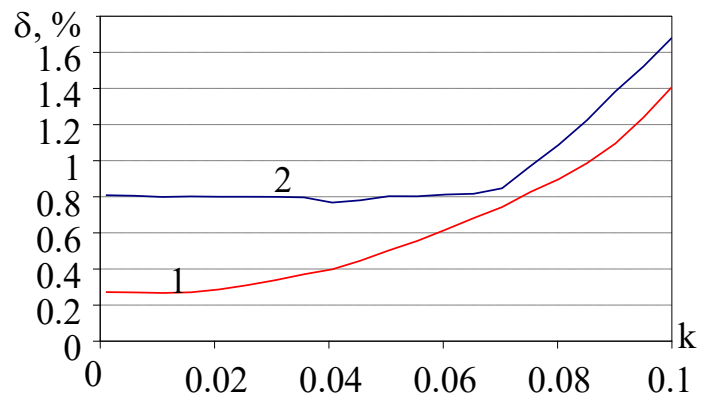

Fig. 3. Mismatch error depending on the multiplier $k$ : $1-\delta_{A \max } ; 2-\delta_{\varphi \max }$

6. Accounting for the effect of the inertial properties of the test-impact formation device on the result of determining the source data

It should be noted that the implementation of algorithms (5) and (6) is based on the use of input impact in the form of the Heaviside function. In real-world conditions, there may be a difference between the input impact on a hydrogen generator and signal (1), which may be due to the inertial properties of the device to change the area of its output hole. It is therefore useful to identify the conditions under which expressions (5) and (6) may be used without significant losses in the accuracy of determining original data, and to devise recommendations to determine the source data for the event when the inertial properties of the device to form a test-impact cannot be neglected. In this case, it is assumed that the characteristics of the inertial properties of such a device are a priori defined. To solve such a problem in the first approximation, it is advisable to use the following expression instead of expression (1)

$$
F(t)=B\left[1-\exp \left(-\frac{t}{T}\right)\right],
$$

where $T$ is the equivalent time constant of the device that forms the input impact on a hydrogen generator, defined $a$ priori. It can also be assigned in the form of specifications for the device.

At such a change in the outlet hole area of a hydrogen generator, there will be a change in the pressure in its cavity, described by expression

$$
P(t)=B K L^{-1}\left[\begin{array}{l}
\left(1-\tau_{1} S\right) \times \\
\times\left[S\left(\tau_{2} S+1\right)(T S+1)\right]^{-1}
\end{array}\right]=B K p(t),
$$

where

$$
\begin{aligned}
& p(t)=1+\left[\left(\tau_{2}-\tau_{3}\right)\left(T-\tau_{2}\right)\left(T-\tau_{3}\right)\right]^{-1} \times \\
& \times\left[\begin{array}{l}
\tau_{2}\left(\tau_{1}+\tau_{2}\right)\left(T-\tau_{3}\right) \exp \left(-\frac{t}{\tau_{2}}\right)-\tau_{3}\left(\tau_{1}+\tau_{3}\right)\left(T-\tau_{2}\right) \times \\
\times \exp \left(-\frac{t}{\tau_{3}}\right)+T\left(\tau_{1}+T\right)\left(\tau_{3}+\tau_{2}\right) \exp \left(-\frac{t}{T}\right)
\end{array}\right] .
\end{aligned}
$$

Next, the algorithm discussed above is implemented to determine the AFC and PFC of a hydrogen generator, that is the operators (2), (5) and (6) are applied to expression (21). The resulting frequency characteristics will contain errors caused by the expression (21) sampling, as well as the inertia of the device that forms the input impact. 
Fig. 4 shows dependences of errors $\delta_{A}$ and $\delta_{\varphi}$ on frequency at $T=0.5 \mathrm{~ms}$ and $T=5.0 \mathrm{~ms}$. Analysis of Fig. 4 shows that at $T$ values commensurate with the time constants $\tau_{i}$ of a hydrogen generator, there is a significant increase in errors when determining its frequency characteristics. Therefore, when forming the input impact on a hydrogen generator, it is necessary that the device that forms this impact should have a time constant that is an order of magnitude less than the minimum value of the $i$-th time constant of a hydrogen generator.

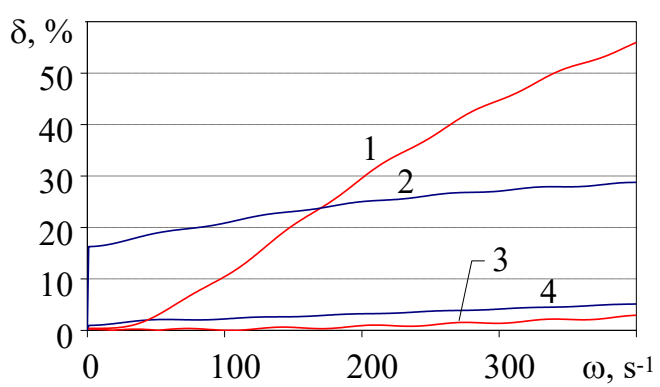

Fig. 4. Mismatch error depending on frequency: $1-\delta_{A}(T=5.0 \mathrm{~ms}) ; 2-\delta_{\varphi}(T=5.0 \mathrm{~ms}) ; 3-\delta_{\mathrm{A}}(T=0.5 \mathrm{~ms})$; $4-\delta_{\varphi}(T=0.5 \mathrm{~ms})$

Fig. 5 shows dependences for the maximum values of errors $\delta_{A}$ and $\delta_{\varphi}$ at $k=0.01 \div 0.1$, where $k$ is determined from expression (18).

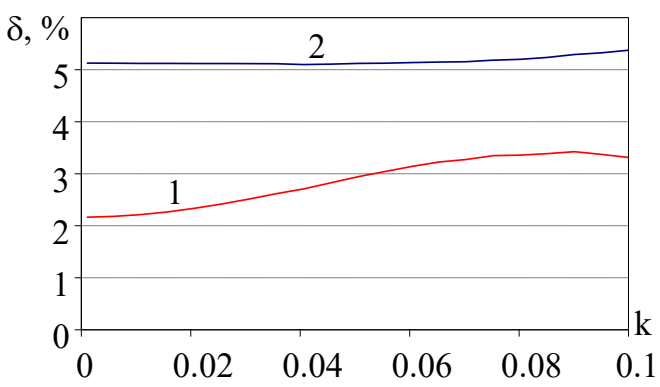

Fig. 5. Mismatch error depending on multiplier $k$ at $T=0.5 \mathrm{~ms}$ : $1-\delta_{\text {Amax }} ; 2-\delta_{\varphi \max }$

From these dependences, it follows that at $T=0.5$ there are $\delta_{A \max } \leq 3.4 \% ; \delta_{\varphi \max } \leq 5.3 \%$, which can be considered acceptable for practice.

It should be noted that the requirements for speed to the device that forms the input impact on a hydrogen generator are quite strict.

One of the most effective methods for easing such speed requirements is to take into consideration the dynamic properties of the device that forms an input impact in the algorithm for determining the frequency characteristics of a hydrogen generator. To do this, one should introduce to expression (4), instead of the Laplace representation of function (1), the Laplace representation of function (19). Upon substitution, we obtain

$$
W_{1}(j \omega)=B^{-1}(1+j \omega T) \sum_{k=0}^{n} \Delta_{k}\left[\begin{array}{l}
\cos [\omega(k+0.5) \tau]- \\
-j \sin [\omega(k+0.5) \tau]
\end{array}\right] .
$$

The magnitude of a time constant is determined a priori. Then the AFC and PFC of a hydrogen generator, taking into consideration the inertia of the device that forms the input impact, will be determined in accordance with algorithms

$$
\begin{aligned}
& A_{1}(\omega)=B^{-1}\left[1+(\omega T)^{2}\right]^{0.5}\left[\left(\sum_{k=0}^{n} \Delta_{k} \cos [\omega(k+0.5) \tau]\right)^{2}+\right. \\
& \left.+\left(\sum_{k=0}^{n} \Delta_{k} \sin [\omega(k+0.5) \tau]\right)^{2}\right]^{0.5} ; \\
& \phi_{1}(\omega)= \\
& =\operatorname{arctg} \omega T-\operatorname{arctg}\left[\left[\sum_{k=0}^{n} \Delta_{k} \sin [\omega(k+0.5) \tau]\right] \times\right. \\
& \left.\times\left[\sum_{k=0}^{n} \Delta_{k} \cos [\omega(k+0.5) \tau]\right]^{-1}\right]= \\
& =\operatorname{arctg}\left[\left[\sum_{k=0}^{n} \Delta_{k}[-\omega T \sin [\omega(k+0.5) \tau]-\right.\right. \\
& \times\left[\sum_{k=0}^{n} \Delta_{k}\left[\begin{array}{l}
\cos [\omega(k+0.5) \tau]+ \\
+\omega T \sin [\omega(k+0.5) \tau]]
\end{array}\right] \times\right.
\end{aligned}
$$

In the implementation of these algorithms, compared to algorithms whose formalization was carried out in the form of expressions (5) and (6), there will be an additional error. This error is due to the inaccuracy in determining the magnitude for time constant $T$. However, the magnitude of this error can be ensured to be commensurate with the sampling error. This approach to determining the source data for implementing the algorithm for controlling the technical condition of a hydrogen generator is appropriate when the $T$ parameter is commensurate in the magnitude, or exceeds, the values for time constants $\tau_{i}$.

\section{Discussion of results obtained when preparing the source data}

Frequency characteristics are used as the source data that underlie the formation of an algorithm to control the technical condition of a hydrogen generator. In contrast to the classic approach to determining frequency characteristics, an indirect method for determining them has been used. This method is based on the use of an array of data, derived from measurements of the transition function of a hydrogen generator at the a priori set time moments. The measurements results are used to approximate the transition function of a hydrogen generator with a set of the Heaviside functions (Fig. 1). This procedure makes it possible to formalize the transition from a temporal function to the frequency-dependent functions. The Kotelnikov - Nyquist - Shannon theorem (7) can be used to determine the moments in time at which the hydrogen generator transition function is measured. However, there is an uncertainty in this case, which is associated with the choice of the magnitude for a maximum frequency of the spectral characteristic of the test-impact. To remove this uncertainty, the choice of time moments for measuring the transition function of a hydrogen generator is based on the margin of sampling error. To this end, the procedure for determining the frequency characteristics of a hydrogen generator has been tested. In this case, as the reference frequency characteristics, we used the characteristics that were determined analytically (12) and (13). For the case when the device for the formation of test-impact in 
determining the transition function is inertia-free, the sampling interval of $2.5 \mathrm{~ms}$ yields the mismatch error of frequency characteristics that does not exceed $1.7 \%$ (Fig. 3). If the inertial properties of such a device are not neglected, its model in the first approximation can be approximated by the model of an aperiodic dynamic link (19). For such a case, a mathematical notation of the hydrogen generator output signal (21) was obtained, which is used in the procedure considered for determining its frequency characteristics (23), (24). After solving the test problem, recommendations were received regarding the dynamic properties of the test-impact formation device. These recommendations come down to that the magnitude for an equivalent time constant of such a device should be an order of magnitude less than the highest value of time constant of a hydrogen generator. For the case when this causes difficulties in the technical implementation, a procedure for determining the source data has been developed, which takes into consideration the inertial properties of the device to form a test impact.

The merit of the developed procedures for determining the source data to form algorithms to control hydrogen generators is a short time to implement them. This period equals the time of a transition process, which is $n$ times less than that in the classical method, where $n$ is the number of measurements of a transition function that can reach several tens or hundreds.

The proposed approach to determining the source data to form an algorithm to control the technical condition of a hydrogen generator provides information about its dynamic properties over the entire range of working frequencies. In this case, such information is obtained by moving from a time domain to a frequency domain using computational procedures (5), (6) or (23), (24), provided the margin of error does not exceed a few percent. When using this approach to determine the source data, it is necessary to note that the maximum magnitude for a time constant of a hydrogen generator is about $(10 \div 20) \mathrm{ms}$. This means that fast-acting measuring equipment should be used. In this case, it might prove difficult to convert pressure into an electrical signal. One such difficulty may be the implementation of the inertia-free conversion of signals. In this regard, the current study should be further advanced by taking into consideration the inertial properties of devices that provide a connection between the output signal of a hydrogen generator and the measuring equipment.

\section{Conclusions}

1. A method for determining the source data has been developed, in order to form an algorithm to control the technical condition of a hydrogen generator, which is based on the use of a test-impact in the form of a jump-like change in the area of a hydrogen generator outlet hole, followed by the calculation of its frequency characteristics based on measurements, at discrete time moments, of the transition function of such a generator. This approach reduces the time it takes to determine the source data by 2 to 3 orders of magnitude compared to the classical method.

2. Recommendations have been developed to select the interval of discreteness in the formation of an array of data used to determine the source data in the hydrogen generator control algorithm. It has been shown that for a sampling interval over which the measurement of a transition function is performed, equal to $(0.25 \div 2.5) \mathrm{ms}$, the error in determining frequency characteristics does not exceed $1.7 \%$.

3. It is shown that for the case when the magnitude for a time constant of the device that forms a jump-like test-impact on a hydrogen generator is commensurate to, or exceeds, the values of time constants for this generator, it is necessary to take into consideration the inertial properties of such a device. The inertial properties are taken into consideration by the introduction of an additional multiplier, containing the equivalent time constant of the device, to the analytical expressions for the frequency characteristics of a hydrogen generator.

\section{References}

1. Dli, M. I., Baliabina, A. A., Drozdova, N. V. (2016). Hydrogen energy and development prospects. Alternative Energy and Ecology (ISJAEE), 22, 37-41. doi: https://doi.org/10.15518/isjaee.2015.22.004

2. Rodchenko, V. V., Galeev, A. G., Popov, B. B., Galeev, A. V. (2015). Study of security systems of oxygen-hydrogen propulsion plant test on the stand. Alternative Energy and Ecology (ISJAEE), 20, 42-52. doi: https://doi.org/10.15518/isjaee.2015.20.005

3. Galeev, A. G. (2017). Review of engineering solutions applicable in tests of liquid rocket engines and propulsion systems employing hydrogen as a fuel and relevant safety assurance aspects. International Journal of Hydrogen Energy, 42 (39), $25037-25047$. doi: https://doi.org/10.1016/j.ijhydene.2017.06.242

4. Rusman, N. A. A., Dahari, M. (2016). A review on the current progress of metal hydrides material for solid-state hydrogen storage applications. International Journal of Hydrogen Energy, 41 (28), 12108-12126. doi: https://doi.org/10.1016/j.ijhydene.2016.05.244

5. Ley, M., Meggouh, M., Moury, R., Peinecke, K., Felderhoff, M. (2015). Development of Hydrogen Storage Tank Systems Based on Complex Metal Hydrides. Materials, 8 (9), 5891-5921. doi: https://doi.org/10.3390/ma8095280

6. Lototskyy, M. V., Davids, M. W., Tolj, I., Klochko, Y. V., Sekhar, B. S., Chidziva, S. et. al. (2015). Metal hydride systems for hydrogen storage and supply for stationary and automotive low temperature PEM fuel cell power modules. International Journal of Hydrogen Energy, 40 (35), 11491-11497. doi: https://doi.org/10.1016/j.ijhydene.2015.01.095

7. Dmitriev, A. L., Ikonnikov, V. K. (2017). Hydrogen fueling station using hydrogen generation by aluminum powder hydrothermal oxidation. Alternative Energy and Ecology (ISJAEE), 10-12, 75-85. doi: https://doi.org/10.15518/isjaee.2017.10-12.075-085

8. Abramov, Y. A., Krivtsova, V. I. (2017). To determine the technical state of the gas generator of the hydrogen storage and supply system. Problems of Emergencies, 26, 3-10. 
9. Lototskyy, M. V., Tolj, I., Parsons, A., Smith, F., Sita, C., Linkov, V. (2016). Performance of electric forklift with low-temperature polymer exchange membrane fuel cell power module and metal hydride hydrogen storage extension tank. Journal of Power Sources, 316, 239-250. doi: https://doi.org/10.1016/j.jpowsour.2016.03.058

10. Sabadosh, L., Larkov, S., Kravchenko, O., Sereda, V. (2018). Increasingly Safe, High-Energy Propulsion System for Nano-Satellites. Transactions on Aerospace Research, 2018 (4), 38-44. doi: https://doi.org/10.2478/tar-2018-0028

11. Kotowicz, J., Bartela, Ł., Węcel, D., Dubiel, K. (2017). Hydrogen generator characteristics for storage of renewably-generated energy. Energy, 118, 156-171. doi: https://doi.org/10.1016/j.energy.2016.11.148

12. Zhao, L., Brouwer, J. (2015). Dynamic operation and feasibility study of a self-sustainable hydrogen fueling station using renewable energy sources. International Journal of Hydrogen Energy, 40 (10), 3822-3837. doi: https://doi.org/10.1016/j.ijhydene.2015.01.044

13. Kudryavtsev, P. G., Figovsky, O. L. (2016). System of storage and hydrogen generation for power propulsion systems and cars. Alternative Energy and Ecology (ISJAEE), 13-14, 46-55. doi: https://doi.org/10.15518/isjaee.2016.13-14.046-055

14. Abramov, Y., Borisenko, V., Krivtsova, V. (2017). Design of control algorithm over technical condition of hydrogen generators based on hydro-reactive compositions. Eastern-European Journal of Enterprise Technologies, 5 (8 (89)), 16-21. doi: https://doi.org/ 10.15587/1729-4061.2017.112200

15. Abramov, Y. A., Basmanov, O. E., Salamov, J., Mikhayluk, A. A. (2018). Model of thermal effect of fire within a dike on the oil tank. Naukovyi Visnyk Natsionalnoho Hirnychoho Universytetu, 2, 95-101. doi: https://doi.org/10.29202/nvngu/2018-2/12 